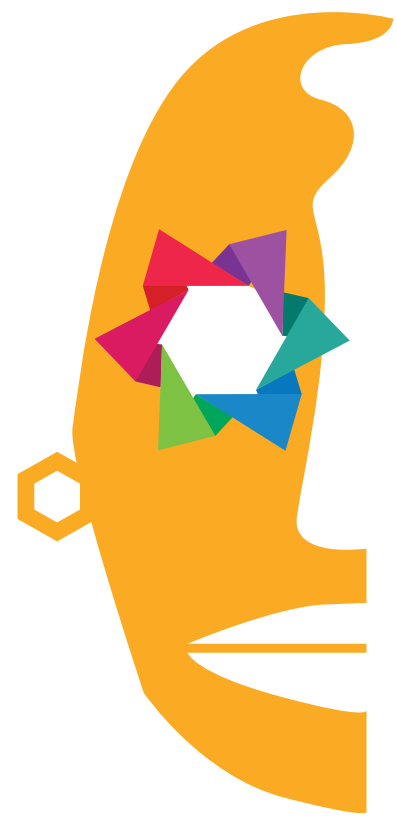

María Antonieta

Benavides Valverde

Periodista sin filiación

institucional

San José, Costa Rica

\title{
Rolando Castellón: el entusiasmo como razón de la creación
}

\section{Rolando Castellón: enthusiasm as the reason for creation}

\section{Resumen}

Las exposiciones de Rolando Castellón han tenido espacio en varias partes del mundo. El artista ha ganado premios en su natal Nicaragua y fuera de ella. Reside en Costa Rica actualmente, y no se ha detenido allí. Se le puede encontrar con varios nombres y con cada uno de ellos desarrolla una actividad distinta, es así de multifacético. Él se ha construido a sí mismo desde su propia experiencia, sin la academia de por medio. Este trabajo quiere dar un recorrido sobre el trabajo y obra del artista.

Palabras clave: Rolando Castellón, arte, Centroamérica, naturaleza, contemporáneo.

\begin{abstract}
The exhibitions of Rolando Castellón have had space in several parts of the world. The artist has won awards in his native Nicaragua and beyond. He currently resides in Costa Rica and has not stopped there. You can find him with several names and each one of them develops an activity, it is that way multifaceted. He has built himself from his own experiences, without the academia. This work wants to give a tour about the work and artwork of the artist.
\end{abstract}

Keywords: Rolando Castellón, art, Central America, nature, contemporary. 
Rolando Castellón nace en 1937 en Nicaragua, sin embargo, el destino lo lleva a Estados Unidos donde se inicia en el arte. Crus (sic) Alegría, Moyo Coyatzin, entre otros nombres, son algunos de los alter ego que usa en sus trabajos; con cada uno de ellos desarrolla actividades diferentes. El artista ha generado obras en pintura e instalación principalmente. Este último género le ha brindado la posibilidad de entablar un diálogo con los artículos que, de forma natural y espontánea, transforma. Como indica Calvo (2014):

No es casual que esa eterna curiosidad y la formación autodidacta misma de Castellón, lo haya hecho explorar con igual intensidad y de una manera sumamente híbrida, ecléctica, desde las raíces ancestrales -visuales, literarias, lingüísticas de su propia cultura, como única manera de rescatar a la vez memoria y resistencia... (párr. 3)

Entre las actividades realizadas por Castellón se encuentra la edición de la revista Expo-See, de la que se hizo cargo. Dicha revista fue un espacio de información comunitario en San Francisco, EE.UU. Actualmente está a cargo de la revista Cenizas que reúne pensamiento y producción. Esta revista surge en 1979 con el título Pséudo-Nym, y los subtítulos Tout est de l'art y One-man thoughs on paper. En sus páginas alberga artículos escritos por el artista, intervenciones de colegas de diferentes partes del mundo y algún "detalle manufacturado" que hace del documento una pieza única, como recalca la curadora Támara Díaz (Herkenhoff et al., 2007, p. 60). Este medio le da voz a los trabajos que no tienen cabida en otros espacios.

Támara Díaz recoge algunos comentarios de personas que están claras de la labor del artista a través de su vida. En el caso de la labor de Castellón en la revista Cenizas, Stefan Baciu expresa:

“Cenizas: Palabras en libertad", revista Tierra y Libertad, México, 1981: "En realidad, Cenizas ha traído con cada número algo de nuevo, insólito e inédito, no tanto gráficamente (no se puede perder de vista el hecho de que Rolando Castellón no es sólo el editor de la revista, sino, al mismo tiempo, tipógrafo, encuadernador, compaginador, administrador y "manager"), sino también poéticamente, por medio de poesías y textos escritos en su mayoría en español y en inglés, pero también en "chicano" y en francés, en alemán y hasta en rumano, alternándose los poemas con dibujos, vigentes o ilustraciones que representan, de cierto modo la "marca" de esta hoja tan simpática, tan singular y tan valiente, porque sabe mantener -en un tiempo cuando desde Nicaragua llega tanta poesía que es más bien cartel político y cursilería- la poesía pluralista que también es lo que suelo llamar la "poesía en libertad". (Díaz, s.f., párr. 62)

Actualmente en San José, Costa Rica, Castellón acoge su propia colección de arte contemporáneo en ARTSéum y mantiene otra fuera de la capital. Su colección 
privada fue exhibida en California State University, Sacramento, en 1977. Algunos de los elementos en exhibición fueron Collected pages from Vogue, Ceramic fragments, Bad slides, Begonia stems, Bread y Knots. La muestra estuvo poco tiempo exhibida, menos de un día. Sobre esta exposición Quirós (2012) comenta:

Las piezas de su colección se encadenan en ese total con una sintaxis propia, permitiéndoles una expresión que va más allá de lo que cada pieza contiene, pues antes está la acción de aquel que ama lo que posee con placer de entendido... (párr. 4)

Figura 1. Autorretrato, 1965, acuarela blanco y negro sobre cartón.

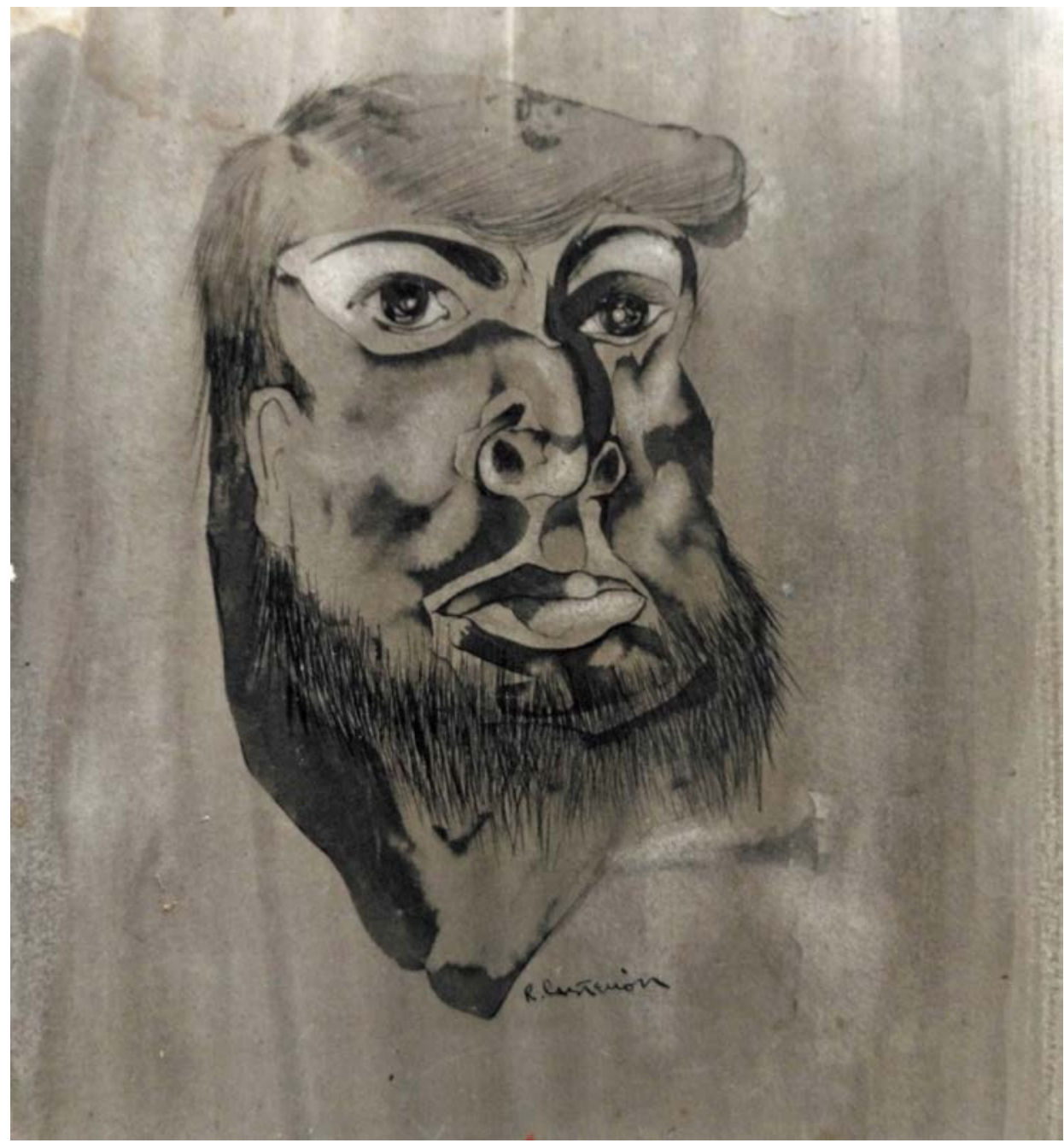

Fuente: Rolando Castellón. 
De igual forma, Castellón tuvo diferentes puestos como curador en jefe del Museo de Arte y Diseño Contemporáneo (MADC) de San José, Costa Rica, entre los años 1994 y 1999. Desde 1969 hasta 1971 fue Co-fundador y Director de Galería de la Raza en California, la cual sigue vigente. Dicha galería fue creada con el fin de competir con otras galerías que no daban espacio a los artistas latinoamericanos.

En 1972, Castellón fue contratado como coordinador del programa Museum Intercommunity Exchange del Museo de Arte Moderno de San Francisco, lugar donde estuvo como curador desde 1972 hasta 1981. Este programa tuvo como objetivo suscitar encuentros entre distintas culturas y difundirlos entre las audiencias del museo. En el periodo donde fue coordinador se realizaron actividades como danza, conferencias, conciertos, actividades experimentales, entre otras.

Figura 2. Ciudad vieja, 1970, carbón sobre cartón

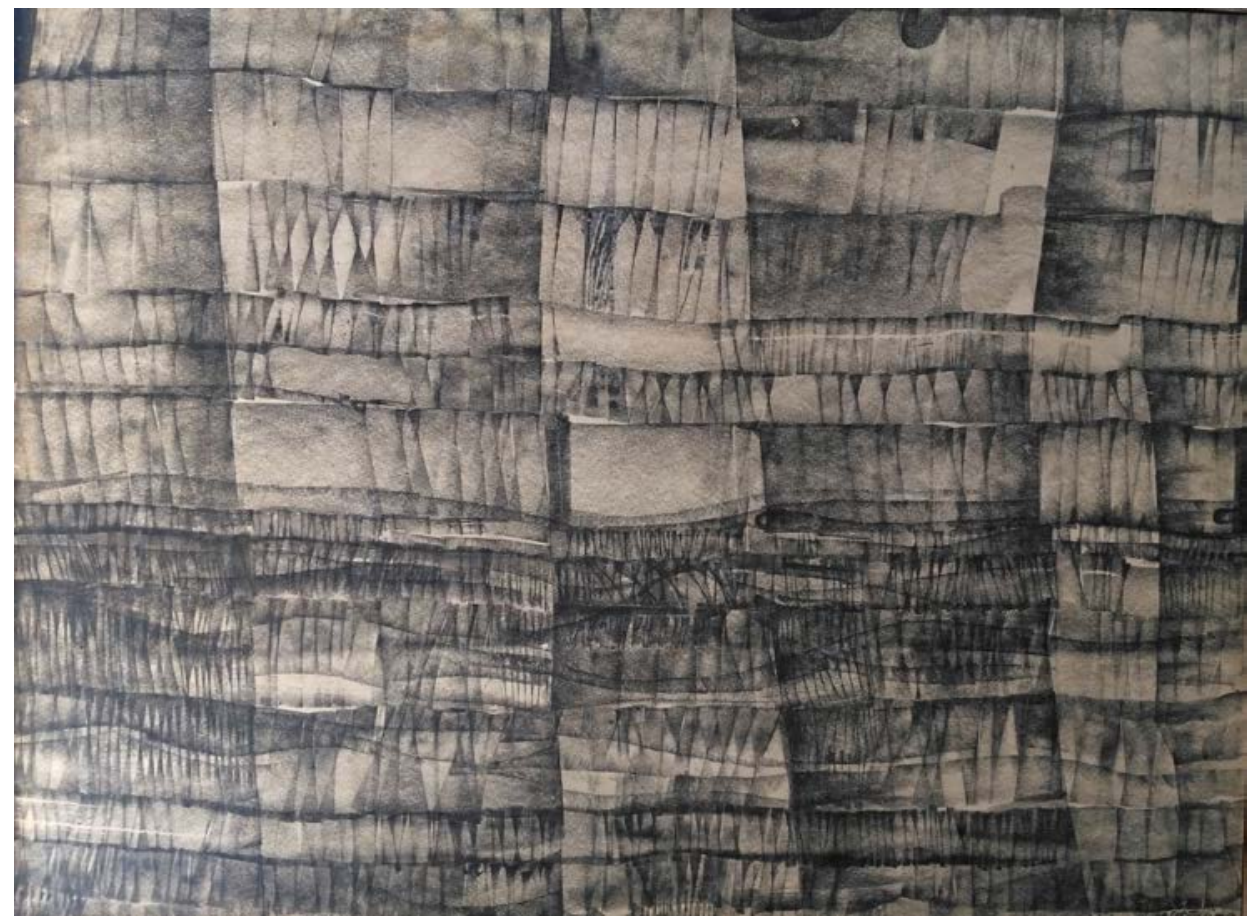

Fuente: Rolando Castellón.

El reconocimiento del trabajo de Castellón ha sido mencionado y reafirmado por varias personas. Díaz (2007) hace referencia a una de ellas: Stephen Goldstine, presidente de San Francisco Art Institute, que el 28 de setiembre de 1979 afirmaba: 
I have known Rolando Castellón for over nine years. In the past decade I have had ample opportunity to observe his professional work and its impact both locally and nationally. During this time the Galería de la Raza became as important as any community gallery in this country. This was due in no small measure to the breathe of Rolando's vision and the serious, effective way he established the Galería from the start. His work at the San Francisco Museum of Modern Art has also had a significant impact both regionally and nationally. His broad experience with not yet established artists, from communities too long ignored by major institutions, served the museum and the art community very effectively. (párr. 60)

Precisamente Castellón desde el puesto en el MADC realiza una curaduría junto con Virgina Pérez-Ratton en 1996 -directora del museo en ese momento-, de la exposición Mesótica II-Centroamérica: Regeneración, con el fin de realizar una investigación sobre el arte del istmo y conocer sobre las nuevas propuestas que surgían en la zona. La muestra reúne a 20 artistas "Sin la pretensión (sic) de ser exhaustiva, sino con el objetivo de presentar lo más fuerte de la producción reciente, faceta aún poco conocida del arte centroamericano contemporáneo" (Museo de Arte y Diseño Contemporáneo, s.f., párr 1). Después de ser realizada la muestra, los artistas involucrados comenzaron a ser invitados a importantes proyectos.

El trabajo realizado en ese momento de la historia es recordado por Luis Fernando Quirós, curador de diseño en el MADC en esa época "Yo siempre he creído que el trabajo que hicimos ahí partió de una necesidad que tenía Centroamérica de tener una voz, de ser visible en el panorama de las artes internacionales" (TEOR/éTica, 2019, 6:59).

En cuanto a Mesótica II-Centroamérica: Regeneración, fue una contestación a la exposición "Ante América" que se origina en Colombia en 1992, y fue exhibida en el MADC dos años después. Dicha exposición reunía a artistas de diferentes países, con la excepción de los países centroamericanos, y pretendía ofrecer una visión del arte contemporáneo de América y también sobre las posiciones problematizadoras que interrogan y eluden lo convencional:

Un buen curador tiene que defender su tesis, primero tiene que tener opinión porque vos haces algo y te lo cuestionan tienes que saber responder, eso es muy importante. Tener la capacidad de escribir linealmente con un tema específico basado en las ideas del artista, su respuesta a lo que ve, (...), tiene que haber la condición de la persona de constancia, comprometido con lo que va hacer. (TEOR/éTica, 2019, 18:05) 
Figura 3. Figura, 1975, crayola sobre papel negro

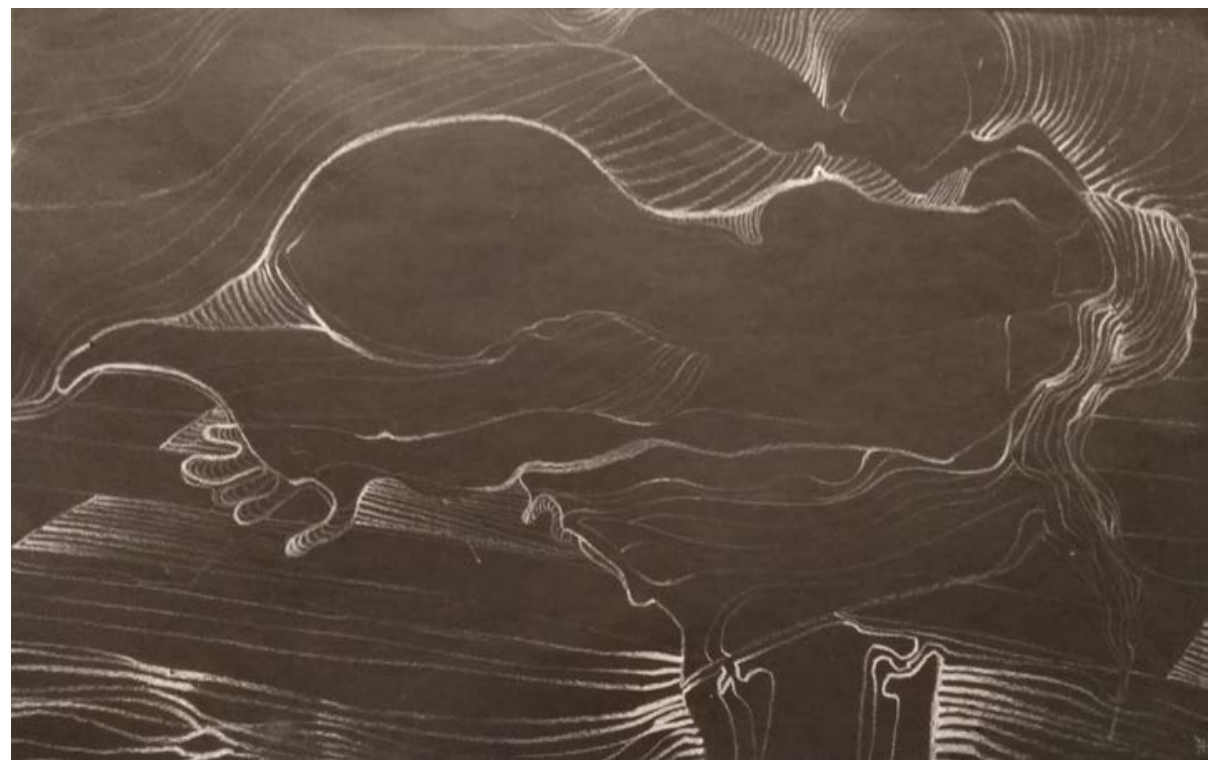

Fuente: Rolando Castellón.

En los años '80 los trabajos realizados por Rolando Castellón se encuentran relacionados con la "pintura matérica" y los objetos que para algunos pueden ser desechos o artículos que pertenecen a otro espacio de la cotidianidad. Castellón lograr darles otro sentido. Al respecto Astiasarán:

... no poseen valor comercial e incluso están en las antípodas de lo que entendemos y fríamente calificamos como 'bello' o 'limpio'. Castellón deja claro que es en su elección donde se exalta la oportunidad del propio material, en su gesto de tocarlo y resignificarlo. (Herkenhoff et al., 2007, p. 95)

En lo que respecta a la selección de materiales, se puede indicar que el artista utiliza cualquier material disponible, lo que para la gente común es un "despojo" para Castellón se puede convertir en una obra de arte. Se trata, a fin de cuentas, de generar con los materiales una unión conceptual de integración con el contexto físico, mediante la armonía y el criterio visual.

"No soy artista, soy un entusiasta" señala Castellón (2019)1. Su obra tiene su origen en cualquier desecho, para algunos ese es su fin natural, sin embargo, para Castellón es su materia prima. Él rescata desechos de su destrucción y, con sus manos, le da otro rol dentro la vida cotidiana. Como él mismo afirma "es la idea de la ecología, es la idea de ayudar a la ecología"2.

1 Entrevista personal 19 de abril, 2019.

2 Entrevista personal 19 de abril, 2019. 
Figura 4. Prisma, 1994, carbón sobre papel

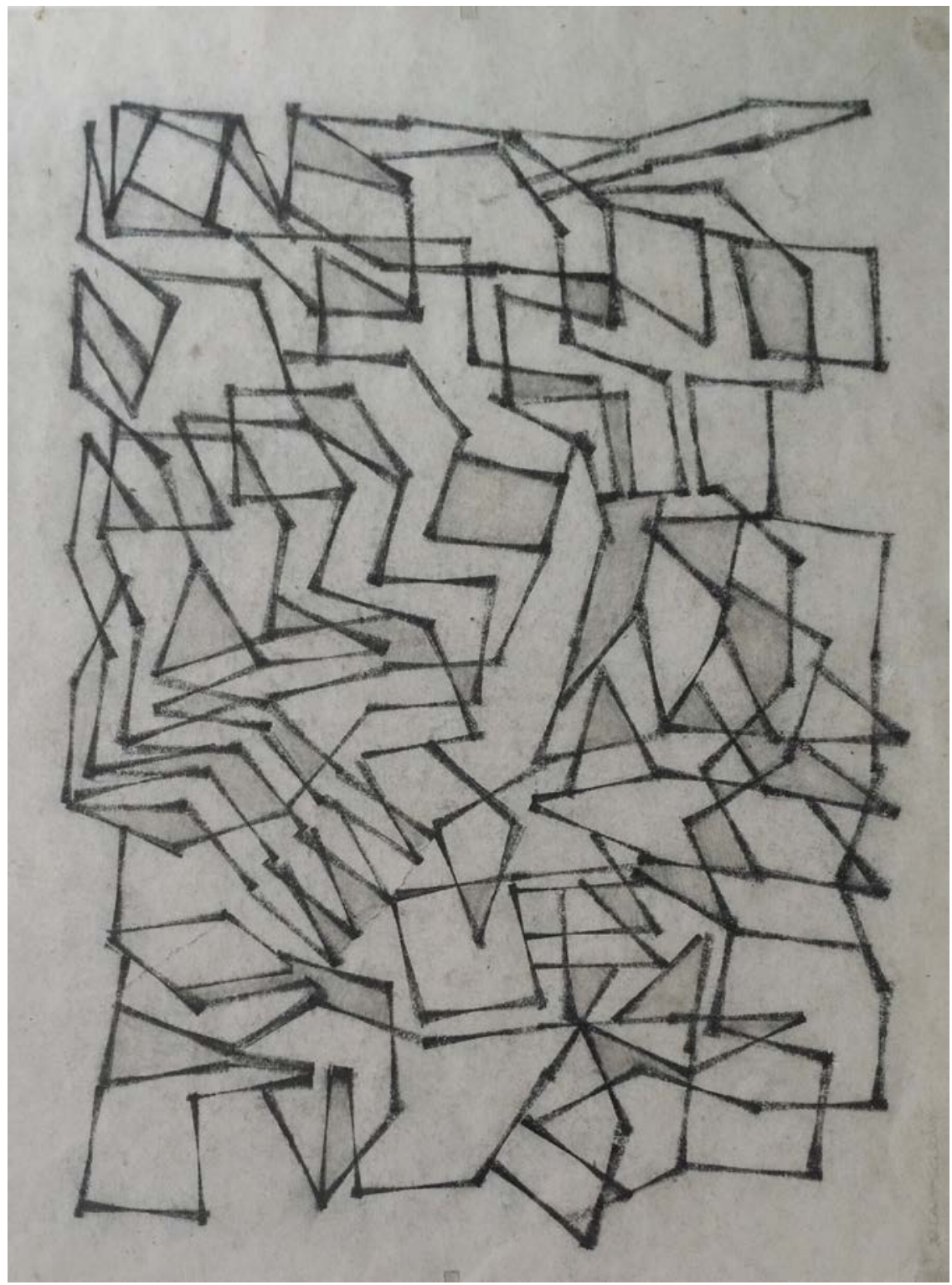

Fuente: Rolando Castellón.

El trabajo constante que ha tenido Castellón durante su vida le ha permitido crear su propia imagen del arte contemporáneo, siempre siendo fiel a él mismo. Su trabajo incesante lo ha convertido en un artista destacado en la región y a nivel internacional. Como indica Quirós (2018): 
... entre tantas otras intervenciones donde forjó esa visión de un arte contemporáneo fogoso, que conceptualiza todo: el espacio, el entorno, la luz, las texturas, los materiales; un arte hecho y mostrado con sencillez, de función lúdica, con alta dosis de desenfado, pero cuestionante, que clava la espina para que se advierta la interrogante ante los grandes asuntos del existir, o ante la incomodidad para con el mismo sistema del arte. (p. 215)

Herkenhoff (2007) en la monografía sobre Castellón publicada por TEOR/éTica, precisa sobre el trabajo del artista, sus criterios de selección y el valor plástico de los mismos, siendo la naturaleza viva una parte importante. La armonía y la semántica desde la naturaleza son parte fundamental de la obra de Castellón, es su materia prima, esta se logra transformar en espacios nuevos, como lo hace ver en el artículo Talento tras las máscaras: "Para mí es importante conservar la belleza o la estética dentro de obras. Yo vengo de una generación muy influida por el modernismo; sin embargo, siempre me he conectado con la naturaleza, que para mí es bellísima” (s.f., párr. 23).

Figura 5. Objeto encontrado (ambos lados), 1985, acrílico, lodo sobre papel Craft

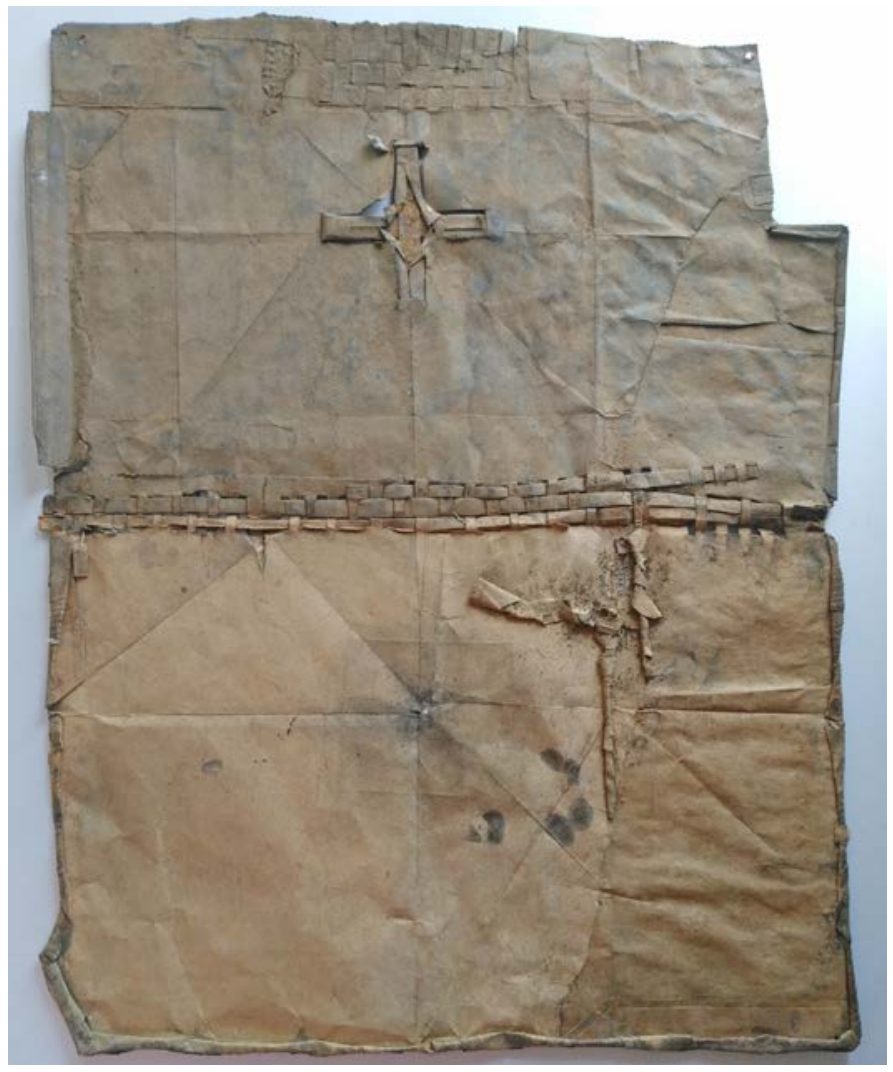

Fuente: Rolando Castellón. 
Figura 6. Objeto encontrado, 1985, acrílico, lodo sobre papel Craft

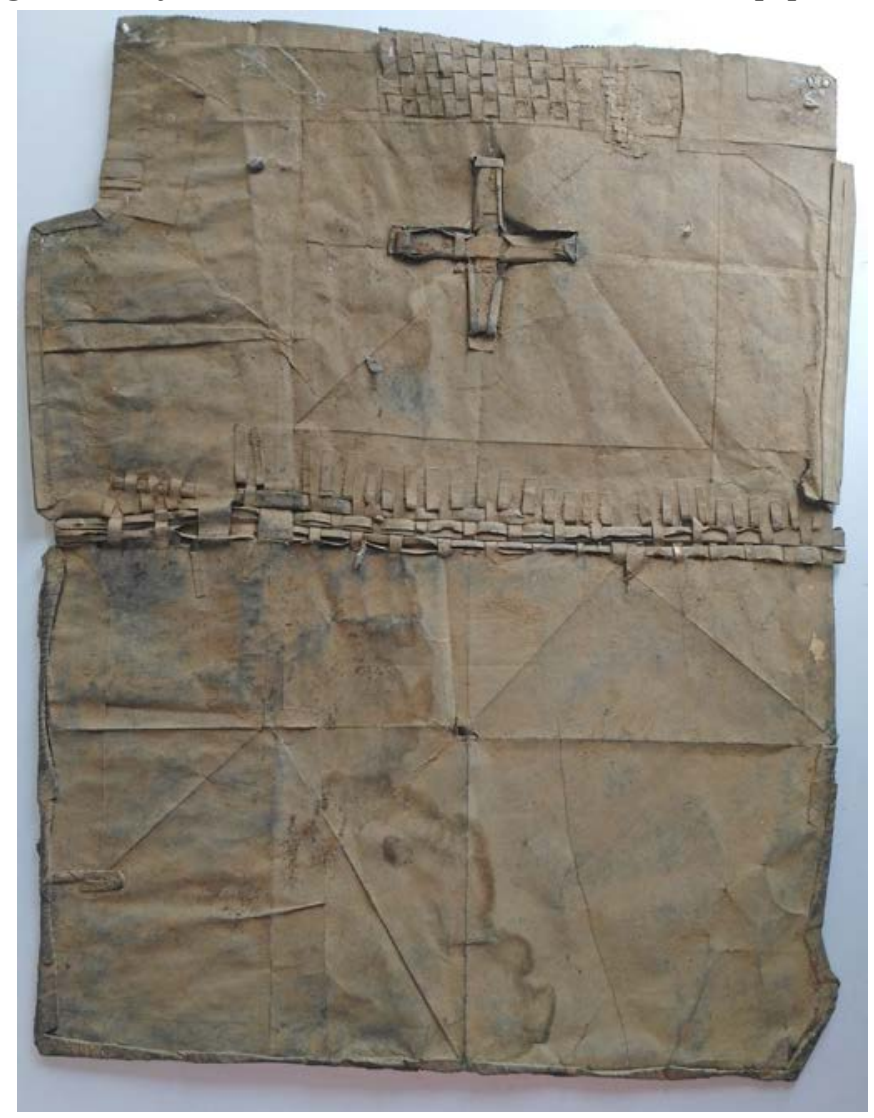

Fuente: Rolando Castellón.

En la obra del artista el elemento del barro es importante, como lo menciona Díaz Bringas (2005), en el artículo que se desprende de la exposición individual realizada en el 2005 en el Museo de Arte y Diseño Contemporáneo (MADC) de San José, Costa Rica, llamada Rastros. Una mirada cíclica:

En la obra de Castellón, el barro aporta no sólo un extraordinario recurso plástico, sino un pensamiento y una posición vital, guiados por un profundo respeto y un verdadero asombro por los misterios de la naturaleza. Por eso, tal vez, prefiere ubicar su intervención en el lazo donde se junta lo natural y lo realizado. Los trabajos con barro, pero también sus múltiples estudios de elementos naturales, se van conformando en el cruce entre el azar y la intencionalidad. Como si prefiriera completar la imagen ya sugerida en la materia misma, Castellón busca en la forma orgánica la base de otras combinaciones. Los elementos naturales y los construidos parecen compartir un juego de espejos: una forma repite la otra y la multiplica. (Díaz Bringas, 2005, párr. 5) 
Figura 7. Marco, 2000, madera de pochote

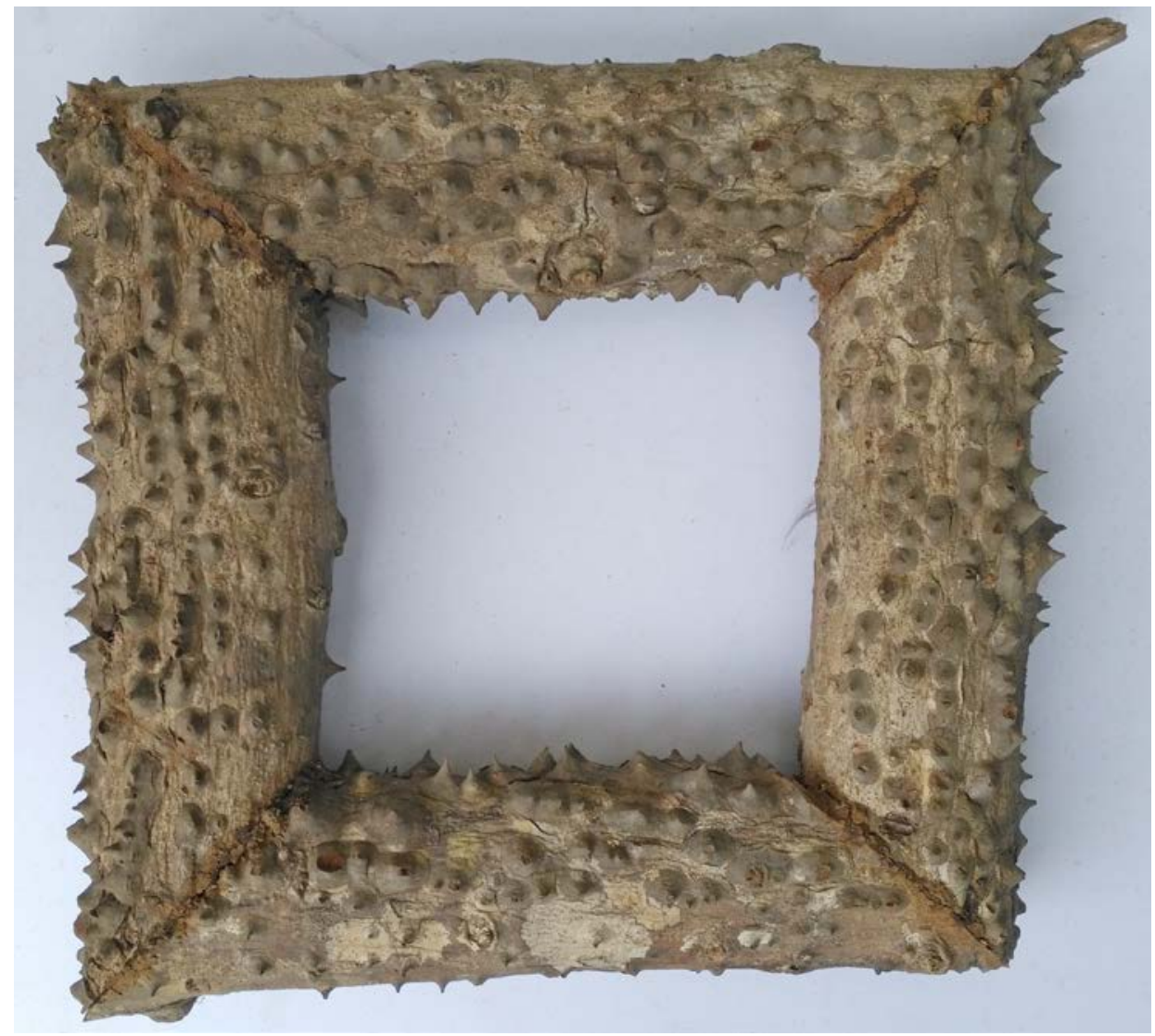

Fuente: Rolando Castellón.

Los trabajos que ha realizado con el barro evocan su niñez en Nicaragua. Con el recuerdo de su infancia revive su diseño, que se puede acercar al de Richard Tuttle o al de Cildo Meireles, como menciona Herkenhoff (2007), quien indica que Castellón posee una intuitiva y clara noción de la percepción, que junto con sus remembranzas logra tomar objetos y darles un nuevo respiro:

Cuando llegué a los Estados Unidos a los 19 años, no sabía ni siquiera quién era Picasso. Era un deslumbramiento. Aquello que era gozo para mí tuvo una repercusión. No tuve dinero para estudiar y tuve que desarrollar mi trabajo. Y hoy lo agradezco porque es el arte el que te va a enseñar ${ }^{3}$. (Herkenhoff et al., 2007, p. 27)

3 Entrevista realizada por Paul Herkenhoff a Rolando Castellón el 27 de agosto de 2002. 
Figura 8. In situ II. 2016. Vidrio, cactus, pintura, collage, zacate, cemento y caja.

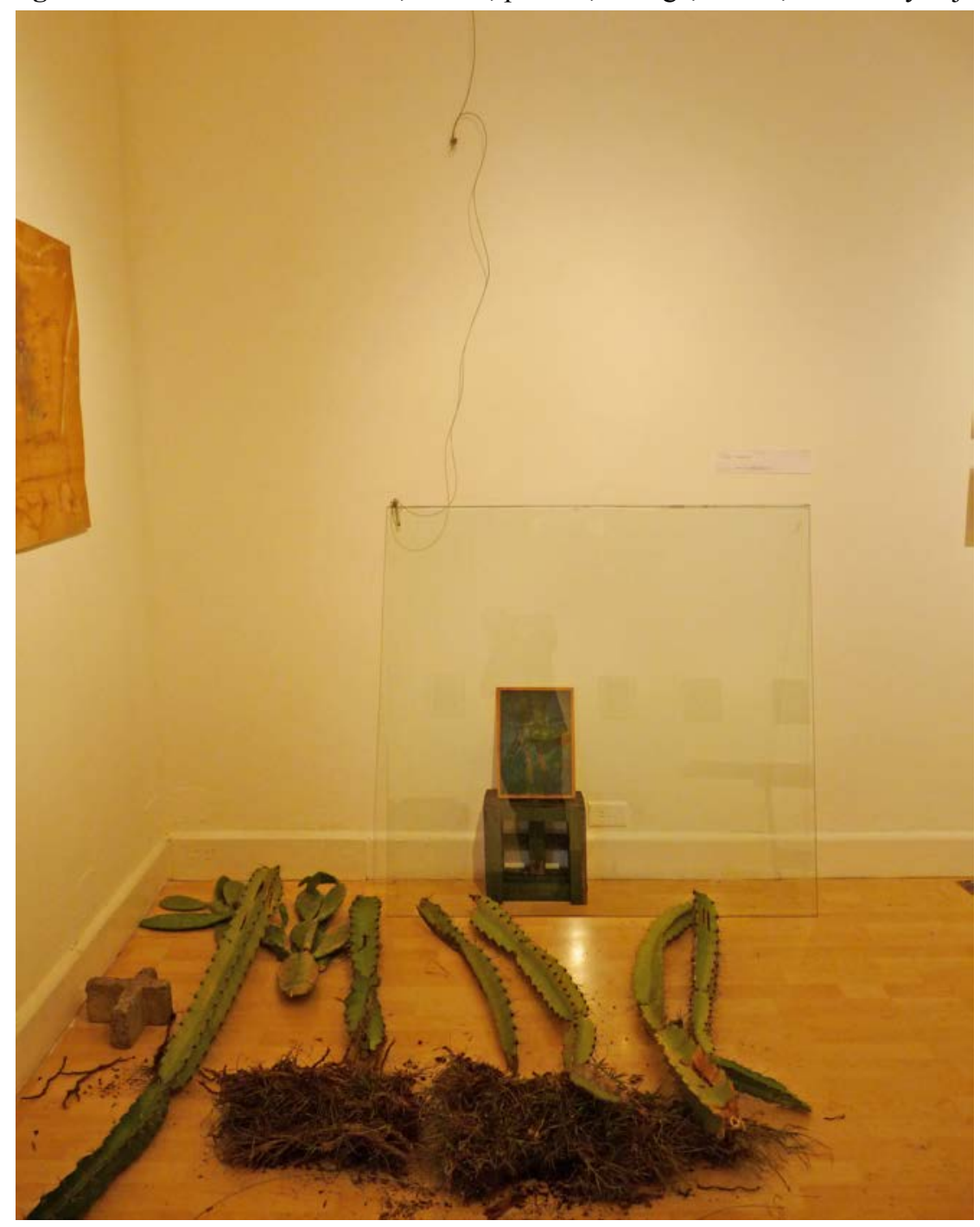

\section{Fuente: Alessadro Valerio.}

Entre otras publicaciones, Luis Fernando Quirós y Rolando Castellón fueron coeditores de la revista La Fanal, publicada por el Centro Regional de Documentación e Investigación en Arte del MADC, entre 1994 y 1997. Durante esa época se editaron 16 ejemplares. Entre sus páginas se podía encontrar reseñas y ensayos sobre el arte contemporáneo centroamericano. Luego publicaron La Fatalísima en el 2015, cuyo nombre evoca el proyecto que se hizo en el museo. Se han publicado 17 ediciones hasta el momento. 
En 1999 la serie Paradojas logra contradecir la percepción del objeto, al observarlo se identifica como metal aquello que es papel higiénico. Las incongruencias forman parte del trabajo de Castellón, como reflexiona Díaz:

Tal vez por eso la presencia insistente en sus obras de las espinas de pochote: una imagen de amenaza y hostilidad que, sin embargo, es también bella y útil, pues el árbol respira por ellas. "Se miente para proteger la verdad", ha escrito Moyo. (Herkenhoff et al., 2007, p. 63)

Figura 9. In Situ, 2016. Ensamblage, acrílico, lodo, metal, objetos y vídeo sobre papel craft.

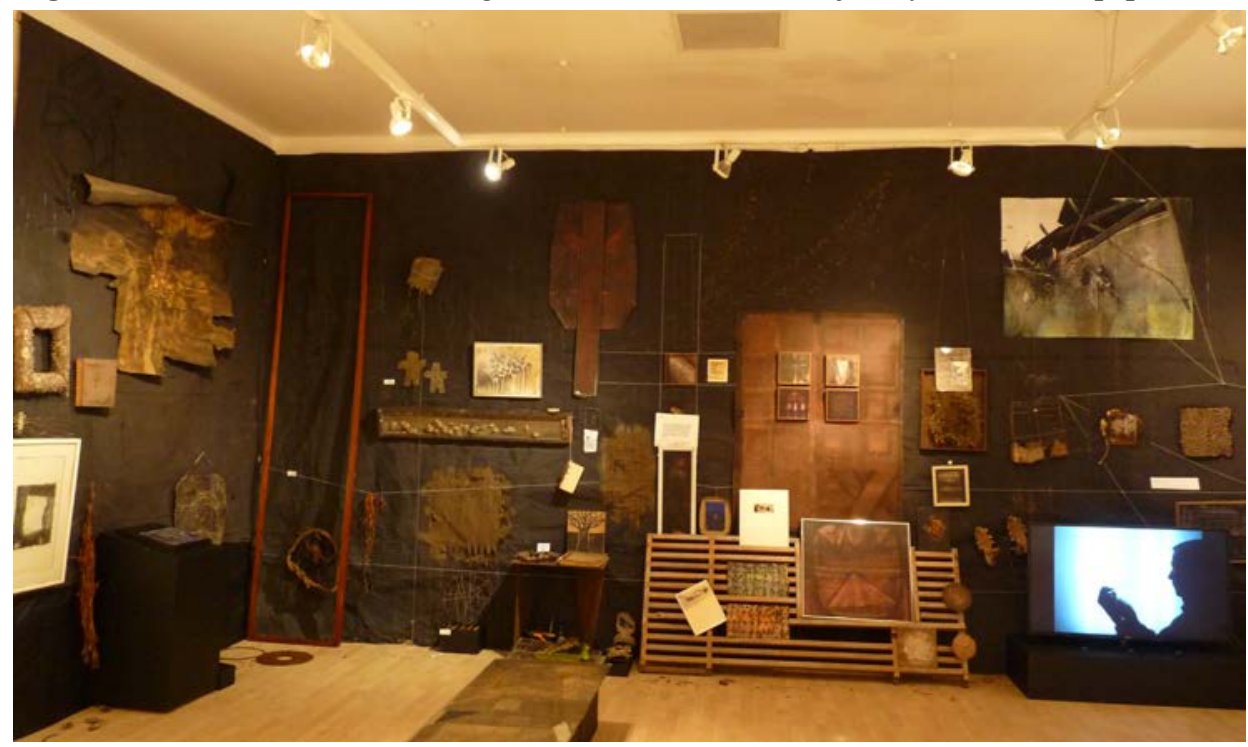

Fuente: Alessadro Valerio.

Díaz rescata la opinión de una de las críticas más prestigiosas de arte en América Latina, Marta Traba, que hizo referencia al trabajo de Castellón en los '70: "una de las más bellas obras sobre papel que se hayan realizado en el continente" (Herkenhoff. et al, 2007, p. 72), a ella se le unieron medios como San Francisco Chronicle en 1974 y 1975, y la Revista California en 1986. Sumado a lo anterior, Rolando Castellón gana con la obra Danza Alegórica, el único premio nacional que no se declara desierto en la Bienal Centroamericana de Pintura de 1971.

En lo que respecta al color en los trabajos de Castellón, se identifica el uso de pigmentos del círculo cromático en algunas obras de la década de los ' 70 , lo que se considera inusitado. Para él ese lapso de tiempo fue uno de los más felices y es cuando inicia con la experimentación del papel doblado.

Tamara Díaz conoce al detalle el trabajo de Castellón y en el 2016, fue el dedicado de la X Bienal Centroamericana en el Museo Nacional de Costa Rica. Para 
ese evento, ella presenta la obra HÁBITAT/ Obra viva como una obra poética del uso de los materiales, asimismo reúne obras y documentos que datan desde la década de los '70:

El trabajo de Castellón propone un hábitat, "lugar de condiciones apropiadas para que viva un organismo, especie o comunidad animal o vegetal." En este espacio de hospitalidad encuentran abrigo tanto elementos orgánicos como las obras de otras artistas, amigos, vecinos y aficionados. (Díaz, 2019, párr. 2)

De igual forma, Castellón junto con Luis Fernando Quirós han trabajado en el proyecto MAYINCA, que es un esfuerzo investigativo que estudia la influencia de la cultura originaria precolombina en el arte moderno y contemporáneo. La primera edición se realiza en el 2013 y la idea fue resaltar la cultura y el arte originario precolombino, además de la producción de las etnias actuales. Todos los años se realiza una nueva edición con diferentes temáticas. Castellón y Quirós se han encargado de la curaduría de cada una de las exposiciones.

Figura 10. Joyas de pobre, 2011.

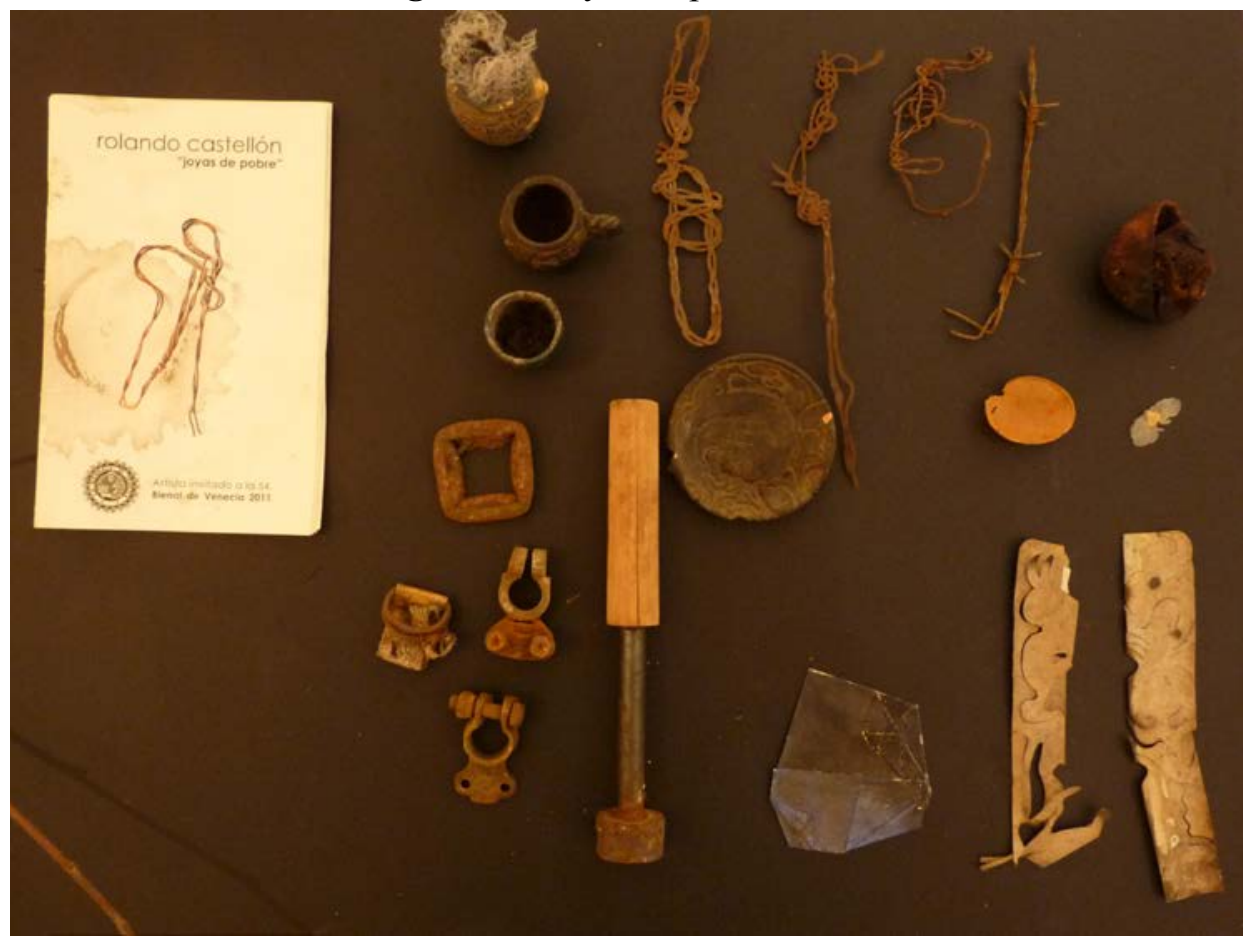

Fuente: Alessandro Valerio. 


\section{a. "La inmedible dimensión del caos: la vida de Rolando Castellón en nosotros"}

Rolando Castellón es una figura importante para el arte centroamericano y latinoamericano, además, es uno de los precursores del centro cultural TEOR/éTica. Esta institución cumple 20 años de fundación en el 2019 y le realizó un merecido homenaje a Castellón por medio de una exposición donde participaron 27 artistas. El resultado fueron 120 piezas inéditas, todas derivaron de una serie de experiencias de pedagogía experimental de los artistas que tuvieron como guía al propio homenajeado. Los curadores encargados de la exposición fueron Gala Berger, Carlos Fernández y Roberto Carter. La muestra estuvo disponible hasta el 3 de agosto del presente año.

A manera de antecedente, Castellón colaboró para la galería con la curaduría de "Curator's Choise: Hallazgos-2004-2006" y en la elaboración del seminario llamado "Temas centrales 1", realizado en el año 2000. Castellón vive en un constate quehacer, adopta el arte desde lo natural porque forma parte de su ser. En sus alter ego, en sus escritos, en sus dibujos, en la colección que tiene... En todo encuentra algo interesante para convertirlo en arte, puede ser caos u orden, depende quien lo esté mirando 4 .

El título del homenaje, "La inmedible dimensión del caos: la vida de Rolando Castellón en nosotros", realizado por el proyecto cultural TEOR/éTica se desprende de un texto de Luis Fernando Quirós sobre Castellón, donde existe una vocación por lo efímero y lo precario que se observa en el uso del barro. A Castellón se le considera un artista impecable, con mucha trayectoria, que realiza obras desde su juventud, tal y como indica Berger (2019): "Una manera de recuperar la memoria, de hacerla viva, como otros artistas pueden cruzarse con este arte, no es solamente una retrospectiva histórica académica de la obra de Rolando, sino es acercarlos a otras generaciones y entablar con diálogo"s.

Para Roberto Carter, Castellón ha puesto en el mapa nuestro pasado precolombino y lo ha mezclado con el concepto del postcolombino, lo que ha permitido que otros artistas exploren desde esa perspectiva artística, utilizando cosas de la cotidianidad latina en general.

De igual forma, Carter recuerda que Castellón enfatiza en que él -ante todo- es un dibujante, además, de que la conexión personal que logra con las cosas es algo indiscutible. Para Castellón el arte es una diversión, él siempre se divierte. Castellón se proyecta en su obra a través del recuerdo y de la nostalgia ${ }^{6}$.

4 Entrevista personal realizada a Gala Berger el 5 de junio del 2019.

5 Entrevista personal realizada a Gala Berger el 5 de junio del 2019.

6 Entrevista personal realizada a Roberto Carter el 30 de mayo de 2019. 
Por su parte Carlos Fernández considera que el lenguaje artístico desarrollado por Castellón es maduro, ya que ha logrado una estética, una obra unificada. Es, sensorialmente, una armonía completa. El ímpetu y la seriedad lo han llevado a ser lo que es hasta la actualidad. También señala Fernández, que Castellón suele mencionar que no planea nada, confía profundamente en lo que hace y esa confianza que tiene es la hace que su obra no tenga errores, como bien apunta: "él suele decir: yo nunca cometo un error, porque yo nunca planeo nada, si planeara podría equivocarme, pero como no planeo lo que estoy haciendo no lleva ningún error"7 (Fernández, 2019).

Figura 11. i . . sí se parece, pero soy yo!, 1969, carbón sobre papel

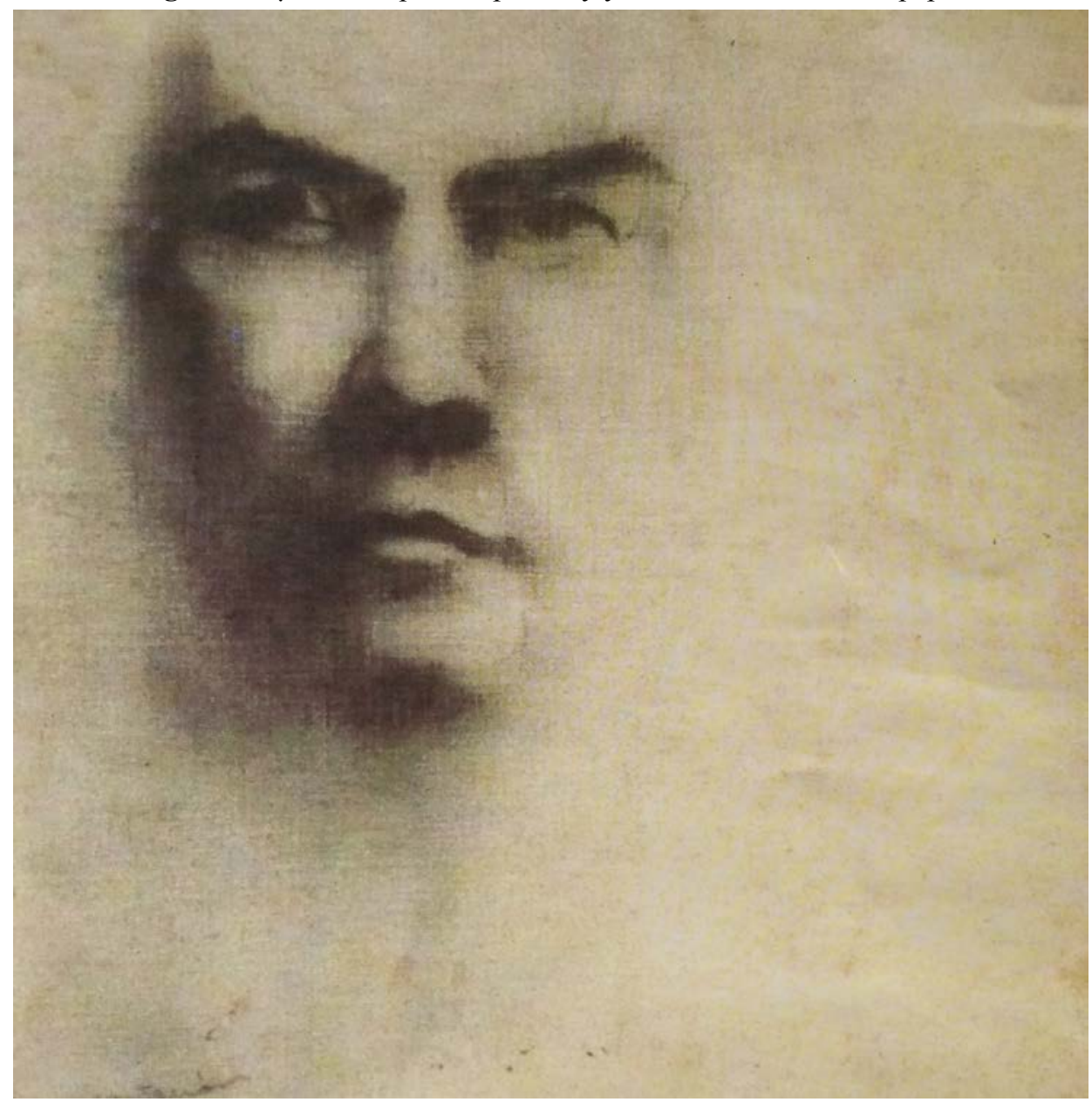

Fuente: Rolando Castellón.

7 Entrevista personal realizada a Carlos Fernández el 5 de junio de 2019. 
Por otro lado, desde Nicaragua el escritor e historiador de arte Jorge Eduardo Arellano, se refiere al trabajo de Rolando Castellón en el siguiente texto publicado en el diario La Prensa de Nicaragua:

Silencioso, radiante, fluido y sutil, el dibujo de Rolando es algo más que un signo ancestral, que un ritmo esencial y una forma más allá de la vida. Funerales, sus imágenes capturan la luz y agreden la visión sin herirla, enriqueciéndola; torrenciales, sin freno ni final, rozan la tragedia y el dolor, dotados de líneas y arcos abracadabrantes, graduando proyecciones tonales, duplicadas e intrincadas, ramificadas y geometrizadas, cayendo en un fondo oscuro y siniestro. Sus rostros y máscaras, fetiches sagrados y misteriosos artefactos son esculturales, monumentales, piramidales. De su conciencia emerge siempre una fuente de vigor y energía. Y su mano derecha pacta con la amistad y un mundo muerto y vivo, ritual y profano, mudo y parlante, antiguo y futurista; un mundo que lleva dentro - muy adentro- de sí. [Madrid, 21 de octubre, 84]. (Arellano, 2016, párr. 4)

Rolando Castellón sigue creando, desde mediados de mayo del presente año viajó a Portugal para darle vida a un proyecto llamado Artes Anónimo, allí estuvo asentado por una temporada y aplicó el tema tanto indígena como de cultura originaria al nuevo proyecto.

\section{Referencias bibliográficas}

Arellano, J. (23 de enero 2016). Nueve Pintores Nicaragüenses. La Prensa. Recuperado de: https://www.laprensa.com.ni/2016/01/23/ cultura/1973952-nueve-pintores-nicaraguenses

Calvo, E. (2014). Estación 13: ese lugar de los des-encuentros. Recuperado de: http://imagen-texto.blogspot.com/2014/05/rolando-castellon-estacion-13-ese-lugar.html

Talento tras las máscaras. (s.f.). Recuperado de: http://www.casamerica.es/ contenidoweb/el-talento-tras-las-mascaras

Díaz, T. (2005). Rastros: Una pelea con la historia. Recuperado de: https://www. madc.cr/es/expo/rastros-una-mirada-ciclica-la-obra-de-rolando-castellon.

Díaz, T. (abril 2018). If Water Didn't Drown a River. Recuperado de: https:// accessions.org/article4/si-el-agua-no-ahogase-un-rio/

Díaz T. (31 agosto 2016). Textos Errantes. Hábitat/ Obra viva de Rolando Castellón Alegría. Recuperado de: https://textoserrantes.wordpress. com/2016/08/31/habitat-obra-viva-de-rolando-castellon-alegria/

Díaz, T. (9 octubre 2007). La verdadera historia de un personaje ficticio; o la historia ficticia de un personaje real. Recuperado de: https://textoserrantes. wordpress.com/2007/10/09/90/ 
Herkenhoff, P., Díaz, T., Pérez, V., Calvo, E. Astiasarán, C, y Quintanilla, R. (2007). Rolando Castellón, 2007. I edición. San José: TEOR/éTica. Recuperado de: https://issuu.com/teoretica/docs/pub_2007_castellon

Museo de Arte y Diseño Contemporáneo. (s.f.) Mesótica II/ Centroamérica re-generación Recuperado de: https://www.madc.cr/es/expo/ mesotica-ii-centroamerica-re-generacion

Museo de Arte y Diseño Contemporáneo. (s.f.) Ante América. Recuperado de: https://www.madc.cr/es/node/1356

Quirós, L. (2010). Rolando Castellón: acercamientos. Recuperado de: https://www.experimenta.es/blog/luis-fernando-quiros/ rolando-castellon-acercamientos-3363/

Quirós, L. (19 marzo 2012). Rolando Castellón: Coleccionar. Recuperado de: https://www.experimenta.es/blog/luis-fernando-quiros/ rolando-castellon-coleccionar-3443/

Quirós, L. (2018). Escena, Revista de las artes. Rolando Castellón, instalación y murales. Vol. 78-Número 1. Julio-diciembre, 197-222.

Sánchez, A. (6 junio del 2019), TEOR/éTica rinde homenaje a uno de sus fundadores. Viva, La Nación, p. 2.

TEOR/éTica. [Teoretica] (31 de julio de 2019). Contextos: Rolando Castellón y Luis Fernando Quirós [Archivo de vídeo]. Recuperado de: https://www. youtube.com/watch? $\mathrm{v}=5 \mathrm{PjB} 3 \mathrm{rlnLz0}$

Valerio, A. (2016). La gráfica y la materia en Rolando Castellón. Un artista nómada que va de vida en vida. Heredia: Universidad Nacional de Costa Rica. 
